\title{
Notch signaling is significantly suppressed in basal cell carcinomas and activation induces basal cell carcinoma cell apoptosis
}

\author{
FENG-TAO SHI ${ }^{1,2^{*}}$, MEI YU ${ }^{1,2^{*}}$, DAVID ZLOTY ${ }^{1,2}$, ROBERT H. BELL $^{3}$, \\ EDDY WANG $^{1,2}$, NOUSHIN AKHOUNDSADEGH ${ }^{1,2}$, GIGI LEUNG $^{1,2}$, ANNE HAEGERT $^{3}$, \\ NICHOLAS CARR ${ }^{4}$, JERRY SHAPIRO ${ }^{1}$ and KEVIN J. McELWEE ${ }^{1,2}$ \\ ${ }^{1}$ Department of Dermatology and Skin Science, University of British Columbia, Vancouver, BC V5Z 4E8; \\ ${ }^{2}$ Vancouver Coastal Health Research Institute, Vancouver, BC V5Z 1M9; ${ }^{3}$ Vancouver Prostate Centre, Vancouver General Hospital, \\ Vancouver, BC V6H 3Z6; ${ }^{4}$ Department of Surgery, University of British Columbia, Vancouver, BC V5Z 1M9, Canada
}

Received October 20, 2015; Accepted September 9, 2016

DOI: $10.3892 / \mathrm{mmr} .2017 .6163$

\begin{abstract}
A subset of basal cell carcinomas (BCCs) are directly derived from hair follicles (HFs). In some respects, HFs can be defined as 'ordered' skin appendage growths, while BCCs can be regarded as 'disordered' skin appendage growths. The aim of the present study was to examine HFs and $\mathrm{BCCs}$ to define the expression of common and unique signaling pathways in each skin appendage. Human nodular BCCs, along with HFs and non-follicular skin epithelium from normal individuals, were examined using microarrays, qPCR, and immunohistochemistry. Subsequently, BCC cells and root sheath keratinocyte cells from HFs were cultured and treated with Notch signaling peptide Jagged1 (JAG1). Gene expression, protein levels, and cell apoptosis susceptibility were assessed using qPCR, immunoblotting, and flow cytometry, respectively. Specific molecular mechanisms were found to be involved in the process of cell self-renewal in the HFs and BCCs, including Notch and Hedgehog signaling pathways. However, several key Notch signaling factors showed significant differential expression in BCCs compared with HFs. Stimulating Notch signaling with JAG1 induced apoptosis
\end{abstract}

Correspondence to: Professor Kevin J. McElwee, Department of Dermatology and Skin Science, University of British Columbia, 835 West 10th Avenue, Vancouver, BC V5Z 4E8, Canada

E-mail: kmcelwee@mail.ubc.ca

*Contributed equally

Abbreviations: BCCs, basal cell carcinomas; HFs, hair follicles; JAG1, Jagged1; GEO, Gene Expression Omnibus; GO, Gene Ontology; GAPDH, glyceraldehyde-3-phosphate dehydrogenase; NOTCH, Notch homolog 1; JAG2, Jagged 2; DVL2, Disheveled 2; HES7, Hairy and Enhancer of Split 7; HRSC, human root sheath cell; HKGS, Human Keratinocyte Growth Supplement; ORS, outer root sheath; IRS, inner root sheath

Key words: basal cell carcinoma, hair follicle, microarray, apoptosis, Notch signaling pathways of BCC cells by increasing Fas ligand expression and downstream caspase- 8 activation. The present study showed that Notch signaling pathway activity is suppressed in BCCs, and is highly expressed in HFs. Elements of the Notch pathway could, therefore, represent targets for the treatment of BCCs and potentially in hair follicle engineering.

\section{Introduction}

The skin is the body's first line of defense, providing protection from dehydration, injury, and infection. It comprises the epidermis and its adjoining structures, including the hair follicle (HF) and its associated sebaceous gland; together comprising the pilosebaceous unit. Hair follicles are self-renewing structures that continuously generate new epithelial cells to replenish the skin and pilosebaceous unit in response to injury (1). Skin homeostasis and wound repair requires the presence of epithelial stem cells as the primary source for regenerative cells. Multipotent stem cells that reside within the epidermis and in the bulge region of HFs (2) can give rise to a variety of cell types, including those forming HFs, interfollicular epidermis, and associated epithelial glands (3). Alterations in either proliferation or differentiation have the potential to disrupt normal skin homeostasis.

Certain disorders of the skin, such as cancer, chronic wounds, skin atrophy, skin fragility, hirsutism, and alopecia, can be, fundamentally, viewed as disorders of skin stem cells (4). It has been hypothesized that tumor formation is the result of inappropriate activation of signaling pathways activating these stem cells or their immediate multipotent progeny (5). Consistent with this view is the observation that several types of skin cancers can be derived from HFs, based on observations of histological presentation and the presence of specific molecular markers common to HFs and skin neoplasias (6). Understanding the molecular mechanisms by which proliferation and differentiation are regulated in skin appendages may provide a useful insight into the molecular basis of disease, and may also identify potential targets for treatment intervention.

Previous findings suggest that a significant subset of basal cell carcinomas (BCCs) are directly HF-derived (7-9). The 
stem cells of the HF bulge region and adjacent cells are a potential primary source of BCCs derived from HFs $(8,10)$. In some regard, HFs and BCCs can be defined as 'ordered' and 'disordered' skin appendage growths, respectively. The primary mechanism, by which most BCCs develop, a constitutive activation of the Hedgehog pathway, is a principal regulatory mechanism in HF development (11). As such, all BCCs, HF-derived or not, may express similar key growth mechanisms to those involved in HF growth and cycling.

An important property that is shared by BCCs and HFs is the ability of cells to repeatedly proliferate, a mechanism that is responsible for maintaining a tumor mass or normal hair fiber production, respectively. If BCCs utilize HF growth mechanisms, growth factors and regulatory networks fundamental to HF growth would also likely be key mediators of BCC growth and may have the capacity to induce BCC growth and invasion. Several specific molecular mechanisms involved in this process of self-renewal, including the sonic hedgehog (Shh), Notch and Wingless-related integration site (Wnt) signaling pathways, have been found to be active in normal HFs and in BCCs (12-16). However, the roles of these signaling pathways in BCC growth, particularly Notch signaling, remain poorly understood.

The present study examined the potential molecular relationships between nodular BCCs and HFs using microarray profiling, reverse transcription-quantitative polymerase chain reaction (RT-qPCR), and immunohistochemistry. It was anticipated that BCCs and HFs would both exhibit activation of common signaling pathways involved in skin appendage formation (genes and networks commonly involved in ordered skin appendage growth). Specific molecular pathway components that code for 'hair follicleness' were also anticipated to be missing or over-represented in BCCs (candidate genes that regulate the networks important in ordered appendage growth that have failed in disordered BCC development). By distinguishing between common pathways and unique pathway components expressed in each type of skin appendage, the aim of the present study was to characterize those components important for BCC growth (genes and networks differentially represented in BCCs not commonly found in healthy skin epithelium or hair follicle appendages) and phenotype presentation, and to identify specific components important for appropriately regulated HF formation.

\section{Materials and methods}

Basal cell carcinomas, hair follicles, non-follicular tissues, and clinical information. All the samples were provided through the Department of Surgery and the Department of Dermatology and Skin Science, University of British Columbia, with approval from the University Clinical Research Ethics Board. Samples of human HFs were collected from scalp biopsies of normal individuals undergoing cosmetic procedures, while nodular BCCs and normal skin were obtained from patients undergoing surgical resection. All the nodular BCC samples and normal skin epithelium were taken from the facial area of donors. Only tissue from patients that had not been treated with preoperative chemotherapy or other therapeutic approaches was selected for analysis. BCC morphological subtypes were described and clinically classified during Mohs surgery and initial diagnoses were subsequently confirmed by formalin-fixed, paraffin-embedded histological assessment of the tumors.

Hair follicles ( $n=10-20 /$ subject) were microdissected to remove the sebaceous gland and upper HF infundibulum and the lower one third, including the hair bulb. The dermal sheath was also removed, leaving the inner and outer root sheaths, including the bulge region, for analysis. Normal skin samples were microdissected to isolate skin epithelium from the dermal component. Samples collected for microarray/qPCR were immediately stored in an RNA stabilization reagent (Qiagen Inc., Toronto, ON, Canada).

RNA isolation. Total RNA was isolated from microdissected tissue or cultured cells with an RNeasy Fibrous Tissue Midi kit (Qiagen Inc.) according to the manufacturer's protocols. The quantity and quality of the RNA was measured using the Agilent 2100 bioanalyzer and RNA 6000 NANO kit (Agilent Technologies, Inc., Santa Clara, CA, USA), and the quantity was measured with a NanoDrop ND-100 spectrophotometer (Thermo Fisher Scientific, Inc., Wilmington, DE, USA).

Microarray production. Human Operon v.2.1 (21K) glass arrays were produced (based on human 70mers from Eurofins MWG Operon Inc., Huntsville, AL, USA) by the Microarray Facility of the Prostate Centre at Vancouver General Hospital (Vancouver, BC, Canada) (17,18). RNAs were amplified using the SenseAmp Plus kit (Genisphere LLC, Hatfield, PA, USA). The 260/280 absorbance ratio was used to determine the appropriate amount of sense RNA for labeling. Total RNA from test samples and universal human reference RNA (Agilent Technologies, Inc.) were respectively labeled with cyanine (Cy) 5 and $\mathrm{Cy} 3$, using the 3DNA array detection 350 kit (Genisphere LLC) and cohybridized to cDNA microarrays. Following overnight hybridization and washing, the arrays were imaged using a ScanArray Express scanner (PerkinElmer, Inc., Waltham, MA, USA).

Microarray data processing and analysis. Arrays were scanned at excitation wavelengths of 532 and $635 \mathrm{~nm}$ to detect the $\mathrm{Cy} 3$ and $\mathrm{Cy} 5$ dyes, respectively. Image analysis and quantification were conducted with Imagene 6.0 commercial software (BioDiscovery Inc, El Segundo, CA, USA). The raw signal and background medians were used as the input for the Genespring 7.2 program (Agilent Technologies, Inc.). GeneSpring allows normalization and multiple filter comparisons of data from different experiments, thus generating restriction lists and the functional classification of differentially expressed genes. Raw data were background corrected and normalized using 'per chip and per spot normalization', which is an intensity-dependent normalization (non-linear or LOWESS normalization) (19). The expression of each gene is reported as the ratio of the value obtained for each sample relative to the universal reference RNA. Data were subsequently filtered using the raw signal strength value of both channels. Measurements with higher signal strength value are relatively more precise than measurements with lower signal strength. Genes that did not reach this value were discarded (100 out of 65,536$)$. A condition tree was generated using hierarchical clustering 


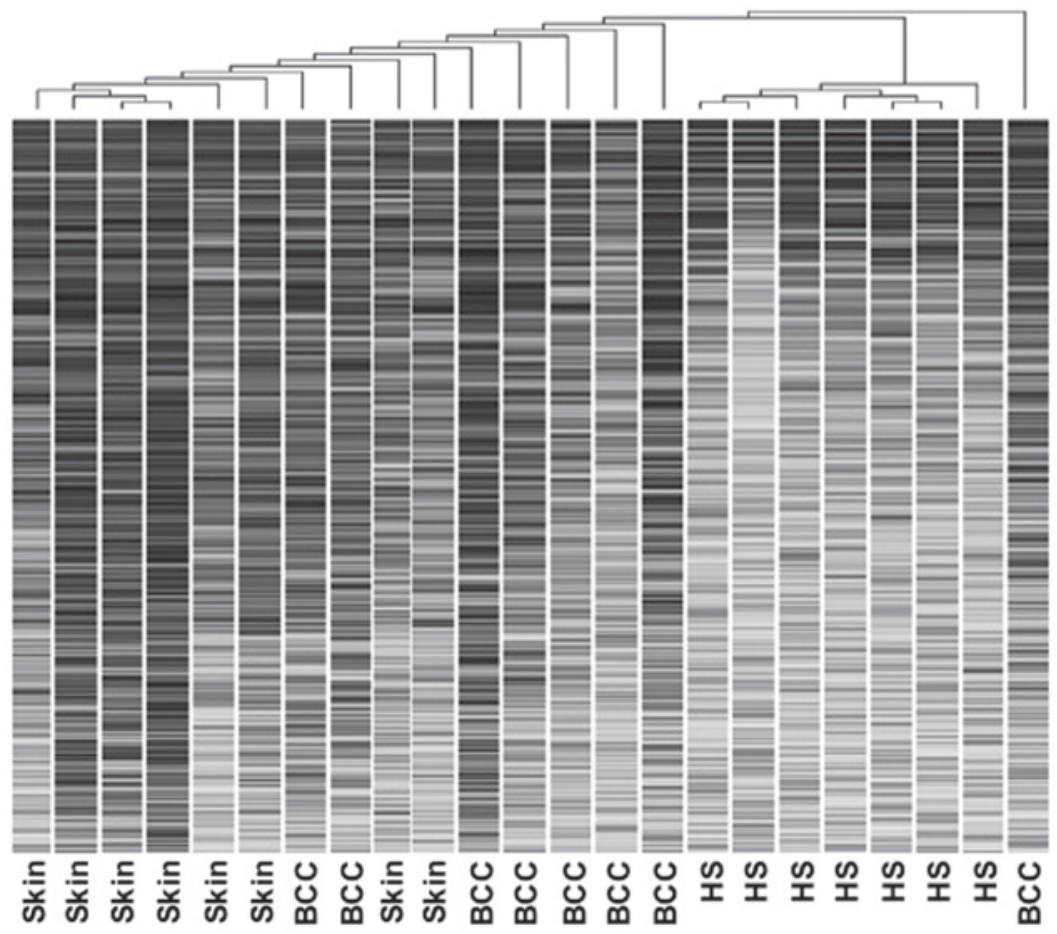

Figure 1. Hierarchical clustering of unfiltered raw microarray data from each sample of hair follicle root sheaths, BCCs and normal skin epithelium. The degree of similarity in gene expression profiles was measured by Pearson's correlation, and distances between clusters were calculated via average linkage. Dendrogram results indicate well-defined cluster groups of cases. HS, hair follicle root sheaths; BCCs, basal cell carcinomas.

of unfiltered data from each sample based on the similarity of their expression data. Similarity was measured using Pearson's correlation, and distances between clusters were calculated via average linkage (Fig. 1). The raw data from the arrays have been entered into the publicly accessible Gene Expression Omnibus (GEO) database in MIAME compliant format (http://www.ncbi.nlm.nih.gov/geo/). The raw data sets are encompassed by a series record number (GSE12542).

Analysis of gene expression differences and similarities. The comparison analyses were conducted by the 'significance analysis of microarrays' (SAM) method (20). Gene expression associated with nodular BCCs $(n=8$ subjects) and HF root sheaths ( $n=7$ subjects) was first evaluated and contrasted (Tables IA and B, and II). The differences analysis between BCCs and HF root sheaths was conducted by the SAM method with a cut-off $q$-value of $14 \%$ and a 2 -fold cut-off (Table IA and B). The 2-fold cut-off was employed to reduce the incidence of false-positive results, which can occur when using $t$-tests (replicates can have similar results by chance), but the probability of which is decreased at higher fold changes. Subsequently, as a prelude to defining the degree of similarity in gene expression between BCCs and HF root sheaths, the cut-off $q$-value was set to be $>40 \%$ and the fold change $<1.5$ (Table II). The cut-off level of $<1.5$ helped to reduce the selection of genes that were not necessarily regulated, but had a sizable error between their replicate values. A comparison analysis between HF root sheaths and skin ( $n=8$ subjects) was conducted by the SAM method (data not shown). SAM was also used to identify genes differentially regulated between $\mathrm{BCC}$ and the normal skin samples as demonstrated in a previous study (21).
Gene ontology analysis. Functional classification of genes was performed using DAVID software $6.70(22,23)$, based on the Gene Ontology (GO) database (www.geneontology.org), to allow the identification of 'enriched' or 'depleted' gene function categories in assigned biological processes, molecular functions, and cellular components $(24,25)$. This program was used to identify genes belonging to different GO categories (derived from Tables I and II). Benjamini-corrected $\mathrm{P}<0.05$ was used as the cut-off for determination of significant gene enrichment in each defined category. $\mathrm{P} \leq 0.05$ indicated that the applied genes listed were specifically associated (enriched) in a category, as opposed to random chance, and were selected. For $25-40 \%$ of the genes defined, no GO annotation was given and their function was unknown. Ontological analyses were performed at biological process category level 3 . The number of genes identified in major categories were normalized by the number of genes annotated in each list and were expressed as percentages (Tables III and IV).

$R T$ - $q P C R$. Total RNA from each sample (1 $\mu \mathrm{g})$ was reverse-transcribed into first-strand cDNA according to the protocol of the Superscript III first-strand cDNA synthesis system (Invitrogen; Thermo Fisher Scientific, Inc., Waltham, MA, USA). The primers used for SYBR Green qPCR were designed using the Prime Time qPCR Primer Design Software (Integrated DNA Technologies, Inc., Coralville, IA, USA; Table V) and tested with the intron-spanning assay. Assays are defined as intron-spanning if at least one exon/exon border is either directly covered by one primer or contained between the primer binding sites. Compared to the median spanned intron size $(2.1 \mathrm{~kb})$, the median Real Time ready assay amplicon size (75 bp) is approximately 30-times shorter. In conjunction with 
Table I. Gene transcripts.

A, Top 20 gene transcripts with the highest magnitude fold-change in gene expression upregulation in nodular basal cell carcinomas vs. hair shafts, sorted by the false discovery rate (q-value)

\begin{tabular}{|c|c|c|c|c|}
\hline Gene product description & Gene name & $\begin{array}{c}\text { GenBank } \\
\text { accession number }\end{array}$ & Fold-change & q-value $(\%)$ \\
\hline Dipeptidylpeptidase IV (CD26, adenosine & $D P P 4$ & NM_001935 & 11.13121 & 0 \\
\hline $\begin{array}{l}\text { Rag D protein } \\
\text { deaminase complexing protein 2) }\end{array}$ & $R A G D$ & AL137502 & 8.835887 & 0 \\
\hline DKFZP564O0463 protein & DKFZP564O0463 & AK001693 & 2.87002 & 0 \\
\hline Propionyl coenzyme A carboxylase, $\beta$ polypeptide & $P C C B$ & NM_000532 & 37.27286 & 0.326689 \\
\hline $\begin{array}{l}\text { DEAD/H (Asp-Glu-Ala-Asp/His) } \\
\text { box polypeptide, Y chromosome }\end{array}$ & $D B Y$ & NM_004660 & 18.25926 & 0.326689 \\
\hline Ras homolog gene family, member A & ARHA & NM_001664 & 7.591441 & 0.326689 \\
\hline Ubiquitin-like 3 & $U B L 3$ & NM_007106 & 7.215993 & 0.326689 \\
\hline Baculoviral IAP repeat-containing 3 & BIRC3 & AF070674 & 7.08567 & 0.326689 \\
\hline Small nuclear ribonucleoprotein polypeptide E & SNRPE & NM_003094 & 5.495296 & 0.326689 \\
\hline $\begin{array}{l}\text { Splicing factor, arginine/serine-rich } 10 \\
\text { (transformer } 2 \text { homolog, Drosophila) }\end{array}$ & SFRSIO & NM_004593 & 5.367942 & 0.326689 \\
\hline $\begin{array}{l}\text { Proteasome (prosome, macropain) } \\
26 \mathrm{~S} \text { subunit, non-ATPase, } 5\end{array}$ & PSMD5 & BC014478 & 4.612349 & 0.326689 \\
\hline $\begin{array}{l}\text { Ubiquitously transcribed tetratricopeptide } \\
\text { repeat gene, } X \text { chromosome }\end{array}$ & UTX & NM_021140 & 4.392788 & 0.326689 \\
\hline Methionyl aminopeptidase 2 & METAP2 & NM_006838 & 4.388392 & 0.326689 \\
\hline $\begin{array}{l}\text { Actin related protein } 2 / 3 \text { complex, } \\
\text { subunit } 5(16 \mathrm{kDa})\end{array}$ & $A R P C 5$ & NM_005717 & 3.719303 & 0.326689 \\
\hline Sin3-associated polypeptide, $18 \mathrm{kDa}$ & SAP18 & NM_005870 & 2.477771 & 0.326689 \\
\hline F-box and leucine-rich repeat protein $3 \mathrm{~A}$ & $F B X L 3 A$ & NM_012158 & 6.425926 & 0.523782 \\
\hline$\beta$-2-microglobulin & $B 2 M$ & AK026463 & 5.708535 & 0.523782 \\
\hline $\begin{array}{l}\text { A disintegrin and metalloproteinase } \\
\text { domain } 9 \text { (meltrin } \gamma)\end{array}$ & ADAM9 & NM_003816 & 4.995793 & 0.523782 \\
\hline Lactate dehydrogenase A & $L D H A$ & NM_005566 & 4.698842 & 0.523782 \\
\hline Protein kinase $\mathrm{C}, \zeta$ & PRKCZ & NM_002744 & 4.646151 & 0.523782 \\
\hline
\end{tabular}

B, Top 20 gene transcripts with the highest magnitude fold-change in gene expression downregulation in nodular basal cell carcinomas vs. hair shaft, sorted by the false discovery rate (q-value)

Gene product description

Keratin-associated protein 4.14

Keratin-associated protein 4.10

Keratin-associated protein 3.2

Keratin-associated protein 4.8

Chromosome 20 open reading frame 28

Lymphotoxin $\alpha$ (TNF superfamily, member 1)

Desmoplakin (DPI, DPII)

Suppressor of Ty 5 homolog (S. cerevisiae)

Neuronal protein 17.3

Leucine zipper protein 1

Breast carcinoma amplified sequence 1

Ubiquitin fusion degradation 1-like

D component of complement (adipsin)

Ribosomal protein S8

LIM and cysteine-rich domains 1
Gene name

KAP4.14
KAP4.10
KRTAP3.2
KRTAP4.8
C20orf 28
LTA
DSP

SUPT5H

P17.3

LUZPI

$B C A S 1$

UFDIL

$D F$

RPS8

$L M C D 1$
GenBank

accession number Fold-change q-value (\%)

$\begin{array}{ccl}\text { NM_033059 } & 0.014887 & 0 \\ \text { NM_033060 } & 0.018098 & 0 \\ \text { NM_031959 } & 0.026814 & 0 \\ \text { AJ406940 } & 0.055245 & 0 \\ \text { NM_015417 } & 0.061437 & 0 \\ \text { NM_000595 } & 0.079272 & 0 \\ \text { NM_004415 } & 0.087855 & 0 \\ \text { NM_003169 } & 0.089178 & 0 \\ \text { NM_019056 } & 0.095102 & 0 \\ \text { BC002428 } & 0.097131 & 0 \\ \text { NM_003657 } & 0.097779 & 0 \\ \text { NM_005659 } & 0.098738 & 0 \\ \text { NM_001928 } & 0.11378 & 0 \\ \text { AK023362 } & 0.138395 & 0 \\ \text { NM_014583 } & 0.149755 & 0\end{array}$


Table I. Continued.

B, Top 20 gene transcripts with the highest magnitude fold-change in gene expression downregulation in nodular basal cell carcinomas vs. hair shaft, sorted by the false discovery rate (q-value)

\begin{tabular}{lccc}
\hline Gene product description & \multicolumn{2}{c}{$\begin{array}{c}\text { GenBank } \\
\text { accession number }\end{array}$} & Fold-change \\
\hline q-value (\%) \\
Elutamate receptor, metabotropic 2 & GRM2 & NM_000839 & 0.153922 \\
Ribosomal protein L38 & EFNB2 & NM_004093 & 0.157336 \\
Loss of heterozygosity, 12, chromosomal region 1 & RPL38 & NM_000999 & 0.157418 \\
& LOH12CR1 & NM_058169 & 0.169164 \\
\hline
\end{tabular}

Table II. Top 20 gene transcripts with the fold-change most consistently close to 0 between nodular basal cell carcinomas and hair shafts, sorted by the false discovery rate (q-value).

\begin{tabular}{|c|c|c|c|c|}
\hline Gene product description & Gene name & $\begin{array}{l}\text { GenBank } \\
\text { accession number }\end{array}$ & Fold-change & q-value (\%) \\
\hline Proteasome (prosome, macropain) subunit, $\alpha$ type, 4 & PSMA4 & AK055714 & 1.001521 & 38.71807 \\
\hline Calcium channel, voltage-dependent, $\beta 1$ subunit & $C A C N B 1$ & M92303 & 1.001613 & 38.71807 \\
\hline Leucine-zipper-like transcriptional regulator, 1 & LZTRI & NM_006767 & 1.001924 & 38.71807 \\
\hline F-box only protein 21 & $F B X O 21$ & NM_033624 & 1.002044 & 38.71807 \\
\hline $\begin{array}{l}\text { Carnitine deficiency-associated gene } \\
\text { expressed in ventricle } 1\end{array}$ & $C D V-1$ & NM_014055 & 1.002094 & 38.71807 \\
\hline $\begin{array}{l}\text { Neurofibromin } 1 \text { (neurofibromatosis, von } \\
\text { Recklinghausen disease, Watson disease) }\end{array}$ & $N F 1$ & NM_000267 & 1.002262 & 38.71807 \\
\hline $\begin{array}{l}\text { Suppression of tumorigenicity } 14 \\
\text { (colon carcinoma, matriptase, epithin) }\end{array}$ & ST14 & NM_021978 & 1.002397 & 38.71807 \\
\hline Ecotropic viral integration site 5 & EVI5 & AF008915 & 1.002636 & 38.71807 \\
\hline Otoraplin & OTOR & NM_020157 & 1.00287 & 38.71807 \\
\hline HEMK homolog $7 \mathrm{~kb}$ & $H E M K$ & NM_016173 & 1.002877 & 38.71807 \\
\hline Complement component 9 & $C 9$ & NM_001737 & 1.003119 & 38.71807 \\
\hline RAB11A, member RAS oncogene family & $R A B 11 A$ & NM_004663 & 1.003131 & 38.71807 \\
\hline B-actin & $A C T B$ & NA & 0.999976 & 48.18056 \\
\hline Homeobox A6 & HOXА6 & NM_024014 & 0.99973 & 48.18056 \\
\hline Pituitary tumor-transforming 1 interacting protein & PTTG1IP & NM_004339 & 0.99972 & 48.18056 \\
\hline Peroxisome biogenesis factor 10 & PEX10 & NM_002617 & 0.999621 & 48.18056 \\
\hline Bombesin-like receptor 3 & $B R S 3$ & NM_001727 & 0.999605 & 48.18056 \\
\hline Doublesex and mab-3 related transcription factor 2 & $D M R T 2$ & NM_006557 & 0.999424 & 48.18056 \\
\hline $\begin{array}{l}\text { High-mobility group (nonhistone chromosomal) } \\
\text { protein 4-like }\end{array}$ & $H M G 4 L$ & AL049709 & 0.998903 & 48.18056 \\
\hline Microfibril-associated glycoprotein-2 & $M A G P 2$ & NM_003480 & 0.99872 & 48.18056 \\
\hline
\end{tabular}

a short amplification time, this size difference can be exploited to gain specificity for mRNA-derived cDNA template vs. template-derived from residual genomic DNA. qPCR was performed using the Applied Biosystems StepOnePlus Real-Time PCR System (Applied Biosystems; Thermo Fisher Scientific, Inc.) according to the manufacturer's protocol. The thermal cycling conditions consisted of $2 \mathrm{~min}$ at $50^{\circ} \mathrm{C}$ and $2 \mathrm{~min}$ at $95^{\circ} \mathrm{C}$, followed by 40 cycles of $95^{\circ} \mathrm{C}$ for $15 \mathrm{sec}$ and $60^{\circ} \mathrm{C}$ for $1 \mathrm{~min}$. Data were analyzed by the comparative threshold cycle method (26) with normalization to human glyc- eraldehyde-3-phosphate dehydrogenase (GAPDH). Changes in gene expression following treatments were recorded as fold differences from values in untreated controls.

Immunohistochemistry. Protein expression coded by Notch homolog 1 (NOTCH1), Jagged 2 (JAG2), Disheveled 2 (DVL2), and Hairy and Enhancer of Split 7 (HES7) was assessed by immunohistochemistry on formalin-fixed, paraffin-embedded biopsies (tissues from 4 individuals per group). Biopsy samples were incubated at room temperature for $1 \mathrm{~h}$ with the following 
Table III. Most commonly identified categories with differences in GO categorization analysis between nodular basal cell carcinomas and hair shafts at GO level 3.

\begin{tabular}{|c|c|c|c|c|}
\hline GO category & $\begin{array}{l}\text { Number of genes } \\
\text { in category }\end{array}$ & $\begin{array}{l}\text { Percentage of total } \\
\text { genes in gene set }\end{array}$ & P-value & Benjamini \\
\hline Regulation of cellular process & 966 & 24.8 & $3.50 \mathrm{E}-13$ & $2.90 \mathrm{E}-10$ \\
\hline Negative regulation of cellular process & 297 & 7.6 & $5.20 \mathrm{E}-12$ & $1.50 \mathrm{E}-09$ \\
\hline Negative regulation of biological process & 308 & 7.9 & 4.30E-12 & $1.80 \mathrm{E}-09$ \\
\hline System development & 417 & 10.7 & $1.00 \mathrm{E}-09$ & 2.10E-07 \\
\hline Regulation of programmed cell death & 147 & 3.8 & $3.30 \mathrm{E}-07$ & $5.60 \mathrm{E}-05$ \\
\hline Positive regulation of cellular process & 243 & 6.2 & $5.20 \mathrm{E}-07$ & $6.30 \mathrm{E}-05$ \\
\hline Positive regulation of biological process & 266 & 6.8 & $5.00 \mathrm{E}-07$ & $7.00 \mathrm{E}-05$ \\
\hline Biopolymer metabolic process & 1090 & 27.9 & $8.30 \mathrm{E}-07$ & $7.80 \mathrm{E}-05$ \\
\hline Organ development & 301 & 7.7 & 8.00E-07 & $8.40 \mathrm{E}-05$ \\
\hline Anatomical structure morphogenesis & 269 & 6.9 & $1.30 \mathrm{E}-06$ & $1.10 \mathrm{E}-04$ \\
\hline Cell death & 206 & 5.3 & $1.70 \mathrm{E}-06$ & $1.30 \mathrm{E}-04$ \\
\hline Cell cycle process & 187 & 4.8 & $2.70 \mathrm{E}-06$ & $1.90 \mathrm{E}-04$ \\
\hline Organ morphogenesis & 114 & 2.9 & $3.40 \mathrm{E}-06$ & $2.20 \mathrm{E}-04$ \\
\hline Regulation of metabolic process & 628 & 16.1 & $6.60 \mathrm{E}-06$ & $4.00 \mathrm{E}-04$ \\
\hline Regulation of cell cycle & 137 & 3.5 & $9.80 \mathrm{E}-06$ & $5.50 \mathrm{E}-04$ \\
\hline Regulation of cellular metabolic process & 604 & 15.5 & $2.00 \mathrm{E}-05$ & $1.00 \mathrm{E}-03$ \\
\hline Regulation of gene expression & 582 & 14.9 & $2.10 \mathrm{E}-05$ & $1.00 \mathrm{E}-03$ \\
\hline Cell differentiation & 399 & 10.2 & 4.20E-05 & $2.00 \mathrm{E}-03$ \\
\hline Regulation of protein metabolic process & 85 & 2.2 & 4.90E-05 & $2.20 \mathrm{E}-03$ \\
\hline Regulation of cell proliferation & 126 & 3.2 & $7.80 \mathrm{E}-05$ & $3.30 \mathrm{E}-03$ \\
\hline
\end{tabular}

Top twenty categories identified are shown. GO, gene ontology.

primary antibodies: Anti-NOTCH1 (cat. no. ab526271; dilution, 100; Abcam, Cambridge, MA, USA), anti-JAG2 (cat. no. ab60041; dilution, 1:50; Abcam), anti-DVL2 (cat no. sc-13974, dilution, 1:100; Santa Cruz Biotechnology, Inc., Dallas, TX, USA) and anti-HES7 (cat. no. ARP37926_P05; dilution, 1:100; Aviva Systems Biology Co., San Diego, CA, USA). Following incubation, Tris-buffered saline (0.05 mol/l; Dako North America, Inc.) was used to wash the membranes. The antibody expression was then characterized using the Universal Dako Cytomation Labeled Streptavidin-Biotin kit (Dako North America, Inc., Carpinteria, CA, USA), according to the manufacturer's instructions, with 3,3'-diaminobenzidine as the development substrate. For the negative controls, the primary antibody was replaced with mouse immunoglobulin $\mathrm{G}$ at the appropriate dilution. The sections were counterstained with Harris' hematoxylin at room temperature for $30 \mathrm{sec}$ and mounted in Permount (Thermo Fisher Scientific, Inc.). Five visual fields were randomly selected per tissue section for assessment at 400x magnification using a standard pathology microscope (BX40; Olympus Corporation, Richmond Hill, ON, Canada).

Human root sheath cell (HRSC) and BCC cell culture and treatment. HF units were obtained by removing the fat layer; hair bulb and dermal sheath were subsequently removed to expose the outer and inner root sheaths of the HFs. Each tissue was then treated with TrypLE Express (Invitrogen; Thermo Fisher Scientific, Inc.) for $15 \mathrm{~min}$ to dissociate the HF keratinocytes [termed 'human root sheath cells' (HRSCs)] into a single-cell suspension for culturing. Following digestion, the cells from groups of five HFs were combined and cultured in BioCoat collagen-I coated 24-well plates (BD Biosciences, Franklin Lakes, NJ, USA) in 50\% Defined Keratinocyte-serum free medium (Invitrogen; Thermo Fisher Scientific, Inc.) combined with 50\% EpiLife (Invitrogen; Thermo Fisher Scientific, Inc.) with a Human Keratinocyte Growth Supplement (HKGS) kit (Invitrogen; Thermo Fisher Scientific, Inc.). Colonies of HRSCs formed in $\sim 1$ week, during which fresh media were added every 2 days to replenish the culture, and the cells were passaged into T25 collagen-I-coated flasks (BD Biosciences). Human BCCs were isolated from nodular BCC samples and cultured in base medium M154 (Invitrogen; Thermo Fisher Scientific, Inc.) with HKGS, as described (27).

Each time the culture reached $90 \%$ confluence, HRSCs or BCCs were passaged into a T25 flask. At the end of passage 3, HRSCs or BCCs were transferred to BioCoat collagen-I-coated 6-well plates (Corning Incorporated, Corning, NY, USA) with a density of 60,000 cells/ml per well for one day. The next day, the media specific for HRSCs or BCCs were replenished and the cells were incubated with $4 \mathrm{mM}$ recombinant JAG1 or scrambled JAG1 (both from AnaSpec Inc., Fremont, CA, USA) for 3 days. At the end of treatment, the cells were collected for further investigations.

Western blot analysis. Following treatment, the cells were washed twice with ice-cold phosphate-buffered saline and 
Table IV. Most commonly identified categories with similarities in GO categorization between nodular basal cell carcinomas and hair shafts at GO level 3.

\begin{tabular}{|c|c|c|c|c|}
\hline GO category & $\begin{array}{l}\text { Number of genes } \\
\text { in category }\end{array}$ & $\begin{array}{l}\text { Percentage of total } \\
\text { genes in gene set }\end{array}$ & P-value & Benjamini \\
\hline Cellular catabolic process & 317 & 6.5 & $1.50 \mathrm{E}-05$ & $1.70 \mathrm{E}-02$ \\
\hline Cellular nitrogen compound metabolic process & 1015 & 20.7 & $6.40 \mathrm{E}-05$ & $3.40 \mathrm{E}-02$ \\
\hline Cellular macromolecule metabolic process & 1412 & 28.8 & $8.20 \mathrm{E}-05$ & $2.90 \mathrm{E}-02$ \\
\hline Regulation of localization & 194 & 4 & $1.70 \mathrm{E}-04$ & $4.50 \mathrm{E}-02$ \\
\hline Sterol metabolic process & 43 & 0.9 & $2.30 \mathrm{E}-04$ & 4.90E-02 \\
\hline Regulation of cell motion & 72 & 1.5 & $2.40 \mathrm{E}-04$ & $4.20 \mathrm{E}-02$ \\
\hline $\begin{array}{l}\text { Nucleobase, nucleoside, nucleotide and } \\
\text { nucleic acid metabolic process }\end{array}$ & 938 & 19.1 & $3.10 \mathrm{E}-04$ & $4.70 \mathrm{E}-02$ \\
\hline Regulation of cell migration & 63 & 1.3 & $6.20 \mathrm{E}-04$ & $8.00 \mathrm{E}-02$ \\
\hline Regulation of multicellular organismal process & 279 & 5.7 & 8.70E-04 & $1.00 \mathrm{E}-01$ \\
\hline Regulation of locomotion & 69 & 1.4 & $1.10 \mathrm{E}-03$ & $1.10 \mathrm{E}-01$ \\
\hline Regulation of cell communication & 304 & 6.2 & $1.60 \mathrm{E}-03$ & $1.50 \mathrm{E}-01$ \\
\hline Lipid transport & 54 & 1.1 & $1.60 \mathrm{E}-03$ & $1.40 \mathrm{E}-01$ \\
\hline Response to organic nitrogen & 28 & 0.6 & $1.70 \mathrm{E}-03$ & $1.30 \mathrm{E}-01$ \\
\hline Cellular amino acid and derivative metabolic process & 114 & 2.3 & $2.10 \mathrm{E}-03$ & $1.50 \mathrm{E}-01$ \\
\hline Positive regulation of cellular process & 518 & 10.5 & $2.20 \mathrm{E}-03$ & $1.40 \mathrm{E}-01$ \\
\hline Regulation of myeloid cell differentiation & 30 & 0.6 & $2.20 \mathrm{E}-03$ & $1.40 \mathrm{E}-01$ \\
\hline Microtubule organizing center organization & 18 & 0.4 & $2.40 \mathrm{E}-03$ & $1.40 \mathrm{E}-01$ \\
\hline Positive regulation of biological process & 566 & 11.5 & $2.50 \mathrm{E}-03$ & $1.40 \mathrm{E}-01$ \\
\hline Regulation of cellular component organization & 143 & 2.9 & $2.80 \mathrm{E}-03$ & $1.50 \mathrm{E}-01$ \\
\hline Peptide metabolic process & 24 & 0.5 & $3.00 \mathrm{E}-03$ & $1.50 \mathrm{E}-01$ \\
\hline
\end{tabular}

GO, gene ontology.

lysed in an ice-cold $1 \mathrm{X}$ radioimmunoprecipitation assay buffer [10 mmol/1 Tris-HCl (pH 8.0), $140 \mathrm{mmol} / \mathrm{l} \mathrm{NaCl}$, $1 \mathrm{mmol} / \mathrm{l}$ ethylenediaminetetraacetic acid ( $\mathrm{pH} 8.0$ ), $0.5 \mathrm{mmol} / 1$ ethylene glycol-bis ( $\beta$-aminoethyl ether)-N,N,N',N'-tetraacetic acid, $1 \%$ Triton $\mathrm{X}-100,0.1 \%$ sodium dodecyl sulfate (SDS), $0.1 \%$ sodium deoxycholate] containing protease inhibitors (Sigma-Aldrich; Merck Millipore, Darmstadt, Germany). The extract was centrifuged at $16,400 \mathrm{x}$ g for $15 \mathrm{~min}$ at $4^{\circ} \mathrm{C}$ to remove cellular debris, and protein concentrations were determined by Bradford assay (Bio-Rad Laboratories, Inc., Hercules, CA, USA). Protein samples $(20 \mu \mathrm{g})$ were then separated by $10 \%$ SDS-polyacrylamide gel electrophoresis and transferred onto polyvinylidene fluoride membranes (Bio-Rad Laboratories, Inc.). The membranes were blocked at room temperature for $1 \mathrm{~h}$ in Tris-buffered saline containing $0.01 \%$ Tween 20 with $5 \%$ non-fat dried milk, and incubated overnight at $4^{\circ} \mathrm{C}$ with anti-Fas ligand (cat. no. ab68338; dilution, 1:1,000; Abcam) or anti-caspase-8 (cat. no. 9746S; dilution, 1:1,000; Cell Signaling Technology, Inc., Danvers, MA, USA). The membranes were washed, and incubated with 1:15,000-diluted IRDye 680LT anti-rabbit (cat. no. P/N 925-68021) or IRDye 800CW anti-mouse (cat. no. P/N 925-32210) secondary antibodies (LI-COR Biosciences, Lincoln, NE, USA) for $1 \mathrm{~h}$ at room temperature. Signals were detected with the Odyssey infrared imaging system (LI-COR Biosciences). Antiserum to total $\beta$-actin (cat. no. sc-1616; dilution, 1:5,000; Santa Cruz Biotechnology, Inc.) was used as the internal control. Scion
Image Analysis software (version 4.0.3.2; Scion Co., Frederick, MD, USA) was used to determine protein density levels.

Flow cytometric analysis. Apoptosis of JAG1-treated HRSCs and BCCs was quantified using an Annexin V-Propidium Iodide Apoptosis Detection Kit (cat. no. 88-8005-72; eBioscience, Inc., San Diego, CA, USA) according to the manufacturer's instructions. The samples were analyzed following appropriate fluorescence compensation and gating strategies with a FACSCanto-II flow cytometer (BD Biosciences), and analyzed using FlowJo software (version 9.0; FlowJo, LLC, Ashland, OR, USA).

Statistical analysis. Data were presented as the mean \pm standard deviation from at least three sets of experiments (each from a separate subject). qPCR samples were assayed in triplicate for each experiment. Data were analyzed by one-way analysis of variance, followed by Tukey's multiple comparison tests if the overall P-values were significant, using the computer software PRISM (version 6.0c; GraphPad Software, Inc., San Diego, CA). $\mathrm{P}<0.05$ was considered to indicate a statistically significant difference.

\section{Results}

Comparison of sample expression profiles by hierarchical clustering. Unsupervised hierarchical clustering analysis 
Table V. Primer sequences for defined genes.

\begin{tabular}{|c|c|c|c|c|}
\hline Gene name & $\begin{array}{c}\text { Genbank } \\
\text { accession no. }\end{array}$ & Forward primer $\left(5^{\prime}-3^{\prime}\right)$ & Reverse primer $\left(5^{\prime}-3^{\prime}\right)$ & $\begin{array}{l}\text { Amplicon } \\
\text { size }\end{array}$ \\
\hline NOTCH1 & NM_017617 & GAGGCGTGGCAGACTATGC & CTTGTACTCCGTCAGCGTGA & 140 \\
\hline NOTCH2 & NM_024408 & TATTGATGACTGCCCTAACCACA & ATAGCCTCCATTGCGGTTGG & 187 \\
\hline NOTCH4 & NM_004557 & GGGTGAGACGTGCCAGTTTC & CTGGGTGTCAATGGAGAGGGA & 126 \\
\hline DTXI & NM_004416 & GGTGTGGGAGTGTCTGAATGA & CCTGGCGAAACTGGTGCAT & 176 \\
\hline DTX2 & NM_020892 & GCAAGCCTTTCAGATTTGCCC & GCTGGCACAAACTGTCCCTT & 121 \\
\hline$L N X 1$ & NM_032622 & TTGGCTCAGTCCTGCTAACTA & GGAAGGCACCTTTACAGAGTTCT & 80 \\
\hline$D V L 2$ & NM_004422 & GAGGAAGAGACTCCСТACCTG & CGGGCGTTGTCATCTGAAAT & 167 \\
\hline$N U M B$ & NM_001005743 & CTACCTTCCAAGGGACCGAGT & AGCCCGGACGTTTTTAGACAC & 131 \\
\hline$J A G 1$ & NM_000214 & TCGGGTCAGTTCGAGTTGGA & AGGCACACTTTGAAGTATGTGTC & 143 \\
\hline$J A G 2$ & NM_002226 & AGCTGGACGCCAATGAGTG & GTCGTTGACGTTGATATGGCA & 131 \\
\hline$L F N G$ & NM_001040167 & GGGTCAGCGAGAACAAGGTG & GATCCGCTCAGCCGTATTCAT & 140 \\
\hline KRT17 & NM_000422 & GGTGGGTGGTGAGATCAATGT & CGCGGTTCAGTTCCTCTGTC & 158 \\
\hline HESI & NM_005524 & ATGGAGAAAAATTCCTCGTCCC & TTCAGAGCATCCAAAATCAGTGT & 182 \\
\hline HES7 & NM_032580 & CGGGATCGAGCTGAGAATAGG & GCGAACTCCAATATCTCCGCTT & 176 \\
\hline$H R$ & NM_018411 & AGGAGGCCATGCTTACCCAT & CACTATGCTCAGGCATCAGGG & 84 \\
\hline RBPSUHL & NM_014276 & CAGTGCCTCCCAATCCTTTGA & CCTCCCCTCAGAATGGTGGT & 139 \\
\hline$D A A M 1$ & NM_014992 & GGTGGACGAGGTATTTCATTCAT & TCTGAAGCGCAAAGTTGCTATC & 100 \\
\hline МАРК 8 & NM_002750 & AGCAAGCGTGACAACAATTTTT & GAAATGGTCGGCTTAGCTTCT & 175 \\
\hline GLII & NM_005269 & GGCACCATGAGCCCATCTC & ATCACCTTCCAAGGGTTCCTC & 216 \\
\hline GLI2 & NM_005270 & CССАCTCCAACGAGAAACCC & GGACCGTTTTCACATGCTTCC & 96 \\
\hline RACl & NM_198829 & ATCCGCAAACAGATGTGTTCT & CGCACCTCAGGATACCACT & 91 \\
\hline ROCK2 & NM_004850 & TTGGTTCGTCACAAGGCATC & AGGGGCTATTGGCAAAGGC & 130 \\
\hline FASL & NM_000639 & AAAGGAGCTGAGGAAAGTGG & CATAGGTGTCTTCCCATTCCAG & 80 \\
\hline
\end{tabular}

(average linkage method) was applied to the unfiltered datasets from BCCs and normal skin samples from patients undergoing surgical resection, and HF root sheaths from normal individuals undergoing cosmetic procedures. This produced a dendrogram with well-defined cluster groups of cases (Fig. 1). The HF root sheath data were clearly separated from $\mathrm{BCC}$ and normal skin data sets with distinct gene expression profiles, but exhibited close similarity within the group. Normal skin samples also yielded relatively distinctive expression profiles. Compared with the HF root sheath and normal skin, BCCs were less readily identified by computer analysis as a distinct entity. Overall, the segregation of data at the molecular level was consistent with the histological distinction of BCCs, HF root sheaths, and normal skin (Fig. 1).

Analysis of gene expression differences and similarities between basal cell carcinoma and hair follicle root sheaths. Gene expression associated with HF root sheaths and BCCs was evaluated, and the two data sets were directly compared. The results indicated that 4329 genes were differentially expressed in BCCs compared with the HF root sheaths with statistical significance $(\mathrm{P}<0.05)$. Of these, 3562 genes were upregulated and 767 were downregulated in BCCs compared with the HF root sheaths. Tables IA and B show the top 20 genes exhibiting the highest magnitude of fold-change, with those upregulated in Table IA and those downregulated in
Table IB. In addition, the top 20 genes with the fold-change most consistently close to 0 (no change) are listed in Table II.

Similarities and differences in Gene Ontology categorization analysis between basal cell carcinoma and hair follicle root sheaths. Tables I and II were functionally annotated using GO terms, providing a controlled vocabulary to describe genes/gene product attributes to evaluate the potential significance in gene expression functions. The 20 most commonly identified, statistically significant, GO term results (adjusted $\mathrm{P}<0.05)$ for genes significantly differentially or similarly expressed in BCCs compared with the HF root sheaths are listed in Tables III and IV, respectively.

The GO analysis revealed that the differentially expressed genes (Table I) and similarly expressed genes (Table II) in BCCs and HF root sheaths were significantly enriched in the designated functional category of 'developmental process'. For example, significantly differently expressed genes were enriched in 'embryonic morphogenesis development', a subcategory of 'developmental process'. Two-hundred and ninety-seven significantly similarly expressed genes were observed to be associated with 'regulation of multicellular organismal process' and 518 similarly expressed genes were associated with 'positive regulation of cellular process', which are also subcategories under 'developmental process' and 'multicellular organismal development'. 


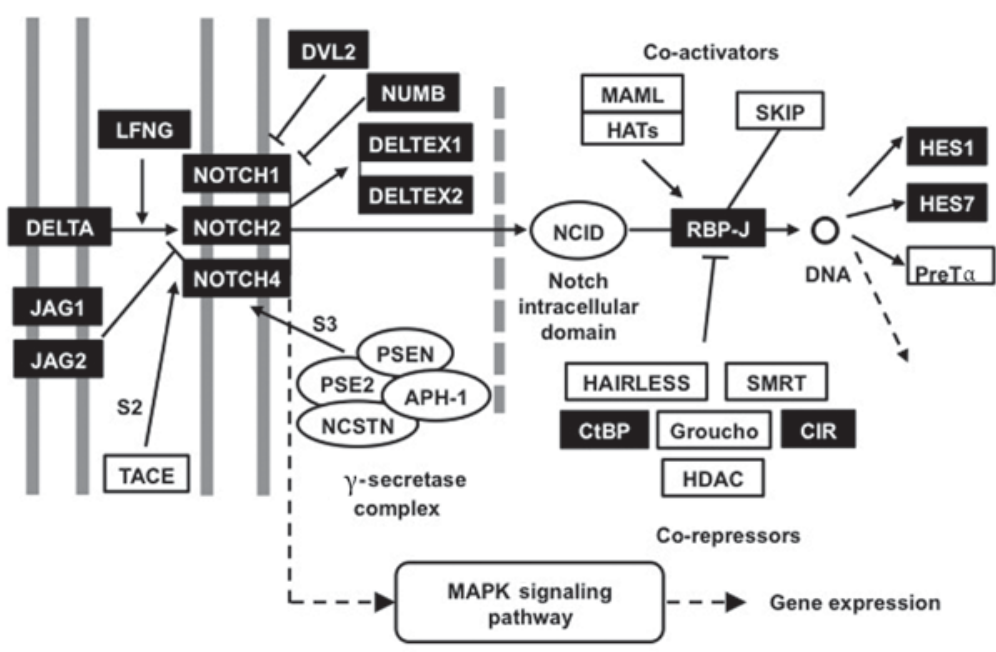

Figure 2. Notch gene signaling pathway interactions. The Notch signaling pathway network was significantly differentially activated in hair follicle root sheaths compared with basal cell carcinomas. Genes and gene sets identified as significantly differentially expressed by microarray are presented with a dark background. JAG, jagged; LFNG, LFNG $O$-fucosylpeptide 3-beta-N-acetylglucosaminyltransferase; TACE, tumor necrosis factor-ACa disintegrin and metalloproteinase metalloprotease converting enzyme; DVL2, dishevelled2; NUMB, NUMB endocytic adaptor protein; PSEN, presenilin; NCSTN, nicastrin; APH, acylaminoacyl-peptide hydrolase; MAPK, mitogen-activated protein kinase; NCID, Notch intracellular cytoplasmic domain; MAML, mastermind-like protein; HAT, histone acetyltransferase; SKIP, Ski-interacting protein; RBP-J, Recombining binding protein suppressor of Hairless; SMRT, Silencing Mediator for Retinoic acid and Thyroid hormone receptor; CtBP, C-terminal binding protein; CIR, CBF1 interacting corepressor; HDAC, histone deacetylase; HES, hairy and enhancer of split.

Enrichment in several gene function categories was commonly identified within significantly differentially expressed genes, including 'cell cycle phase', 'cell cycle process', 'cell death', 'cell differentiation', 'cell maturation', 'G1/S transition of mitotic cell cycle', 'cell motility' and 'cell-cell signaling', under the primary category of 'cellular process' (Table III). In addition, gene enrichment of some subcategories under the term of 'regulation of cellular process' was observed, including 'regulation of cell cycle', 'regulation of cell proliferation', 'regulation of gene expression', 'epigenetic', 'regulation of signal transduction', 'regulation of transcription' and 'regulation of translation' (Table III).

In parallel, of the genes similarly expressed in BCCs and HF root sheaths, numerous genes with a similar expression were observed in gene function subcategories of the term 'cellular process', including 'positive regulation of cellular process', 'regulation of cell communication', 'regulation of multicellular organismal process', 'regulation of cell migration' and 'regulation of localization' (Table IV). Subcategories such as 'cellular amino acid and derivative metabolic process', 'nucleobase, nucleoside, nucleotide and nucleic acid metabolic process' and 'sterol metabolic process', were also found enriched with similarly expressed genes within the category 'metabolic process' (Table IV). The GO analysis also indicated that a number of genes, both similarly and differentially expressed between BCCs and HF root sheaths, are involved in categories under the term of 'positive regulation of cellular process'. The data suggest patterns of gene activity consistent with skin appendages, though with significant distinctions in individual expression of genes between BCCs and HFs.

Biological network and pathway analysis of basal cell carcinoma and hair shafts. To assess which signaling pathways were affected during early gene regulation, the genes in Tables I and II were classified and grouped into pathways, based on pathway information imported from the Kyoto Encyclopedia of Genes and Genomes (KEGG; http://www. genome.jp/kegg/). Pathways that may be involved in both hair morphogenesis and tumorigenesis were the primary focus, based on published knowledge: The Shh, Notch, and Wnt signaling pathways. Based on the gene set that included genes differentially expressed between the HF root sheaths and nodular BCCs (Table I), 6 genes involved in the Shh signaling pathway were identified, 23 genes in the Wnt signaling pathway, and 4 genes in the Notch signaling pathway. Genes with similar trends of expression in BCCs and HF root sheaths were also analyzed (Table II): 11 genes were involved in the Shh signaling pathway, 37 genes in the Wnt signaling pathway and 9 genes were identified in the Notch signaling pathway. The identified pathway-specific genes in the corresponding pathway maps derived from the KEGG database are presented in Fig. 2. Since Notch signaling i) promotes HF differentiation into sebaceous gland and interfollicular epidermal lineages, ii) is known to act as an epidermal tumor suppressor, and iii) genes in this pathway exhibited the most extreme changes in expression/inhibition by microarray, the present study subsequently focused on the Notch signaling pathway.

Validation of the expression of selected genes. Having completed the microarray analysis of BCCs and HFs, 22 genes with known functional significance associated with Notch signaling were selected for evaluation by RT-qPCR (Table VI). Differential Shh pathway gene expression $(G L I 1, G L I 2)$ was also reconfirmed to validate the study. Although the magnitude of change in expression defined by qPCR was different from that observed by microarray, the trends, whether for increased or decreased gene expression, were generally consistent with microarray data (Table VI).

NOTCH1, JAG2, DVL2 and HES7 protein expression in the pathology specimens from BCC patients, scalp/terminal 
Table VI. Selected gene validation results by RT-qPCR with corresponding microarray results for comparison.

Hair follicle vs. skin

\begin{tabular}{|c|c|c|c|c|c|c|c|c|}
\hline \multirow{2}{*}{$\begin{array}{l}\text { Gene } \\
\text { name }\end{array}$} & \multicolumn{2}{|c|}{ Microarray } & \multicolumn{2}{|c|}{ RT-qPCR } & \multicolumn{2}{|c|}{ Microarray } & \multicolumn{2}{|c|}{ RT-qPCR } \\
\hline & Fold change & q-value & Fold change & P-value & Fold change & q-value & Fold change & P-value \\
\hline ООТСНI & 7350142 & 8.64548474 & 89.7796173 & $3.0878 \mathrm{E}$ & 2.25963492 & 55.168 & $3.200 / 3 / 4$ & 0.017 \\
\hline NOTCH2 & 0.49022594 & 0.39254973 & 94.051046 & $2.4841 \mathrm{E}$ & 6324991 & 2.15276566 & 0.87297527 & 0.84563107 \\
\hline NOTCH4 & 2.69005573 & 0.243 & 19.2601231 & 5 & 844966 & & +59359 & 619 \\
\hline DTXI & 1.17722862 & 48.8237978 & 16.3788042 & 0.03308844 & 4295169 & 55.1681869 & 0.28089744 & 0.22707567 \\
\hline DTX2 & 0.99256711 & 40.6530129 & 18.9813992 & 0.00157923 & 0.47607531 & 4.07129257 & 0.43629239 & 0.08540183 \\
\hline$L N X 1$ & - & & & & & & & \\
\hline$D V L 2$ & 816 & 106 & & & 41 & & & 0.035 \\
\hline$N U M B$ & 8845002 & 0.48 & & 4.92 & 366339 & 55.168 & 412783 & 0.634 \\
\hline$J A G 1$ & 149885 & & & & & & & \\
\hline$J A G 2$ & 39265 & 41.2725397 & 179 & & 74 & 55. & 0.3 & 0.23588105 \\
\hline$L F N G$ & 07190237 & 6.92879545 & 2022 & 4.54 & 215 & 55.1 & 184 & 0.61264104 \\
\hline KRT17 & 3.021 & 0.00846 & & $E-09$ & 53 & 69 & 51.4001016 & 0.00100685 \\
\hline HESI & - & & 1067.11032 & $1.053 \mathrm{E}-15$ & 0.76047244 & 67.4104045 & 2.91116399 & 0.0400455 \\
\hline HES7 & 1.19000588 & 48.8237 & 3262.24091 & $1.5035 \mathrm{E}-08$ & 4.16958086 & 29.7263863 & 0.29241452 & 0.13032618 \\
\hline$H R$ & 2.16394516 & 2.23319493 & 226.55094 & $1.0638 \mathrm{E}-09$ & 1.09510072 & 58.338051 & 1.19521471 & 0.76942586 \\
\hline RBPSUHL & 3.11300222 & 41.2725397 & 255.196596 & $7.7485 \mathrm{E}-10$ & 1.22074356 & 55.1681869 & 0.16526889 & 0.06136225 \\
\hline$D A A M 1$ & 0.20611879 & 0.21537795 & 574.06641 & $1.5066 \mathrm{E}-07$ & 0.54865054 & 18.0863137 & 1.63754261 & 0.55059198 \\
\hline МАРК 8 & 1.5501382 & 42.0929177 & 199.824645 & & 0.85527761 & 67.7038487 & 0.96727335 & 0.97161104 \\
\hline GLII & - & - & & & - & - & 1.87408166 & 0.51779197 \\
\hline GLI2 & $\cos >$ & & & & & & 12.2544 & 0.00422916 \\
\hline$R A C l$ & & & & & & & & 0.66627414 \\
\hline ROCK2 & 0.18494564 & 2.62913482 & 575.373988 & $8.4351 \mathrm{E}-07$ & 0.82910219 & 67.7038487 & 1.38128144 & 0.6297566 \\
\hline
\end{tabular}

RT-qPCR, reverse transcription-quantitative polymerase chain reaction.
Basal cell carcinomas vs. skin 


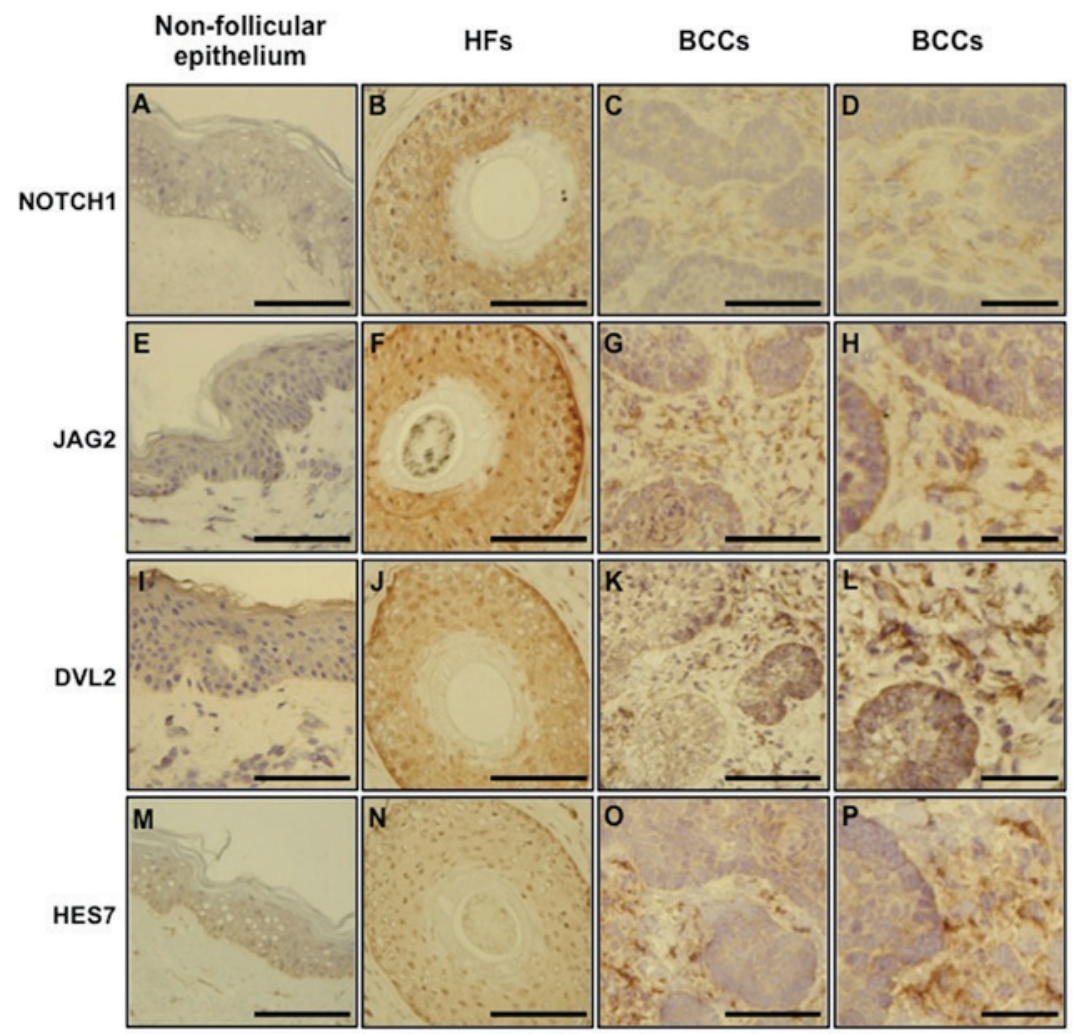

Figure 3. NOTCH1, JAG2, DVL2 and HES7 expression in the normal non-follicular epithelium, hair follicle root sheaths and basal cell carcinomas Immunohistology was conducted to define the expression of NOTCH1, JAG2, DVL2 and HES7 in pathology specimens of normal non-scalp skin, normal scalp/terminal HF biopsies, and BCCs. All of the primary antibodies exhibited a greater intensity of labeling in terminal HFs compared with nodular BCCs and non-scalp skin when tissues were processed in parallel. Scale bar, $100 \mu \mathrm{m}$ (except D, H, L and P, where the scale bar is $40 \mu \mathrm{m}$ ). JAG2, Jagged2; DVL2, Dishevelled2; HES7, hairy and enhancer of split 7; HF, hair follicle; BCCs, basal cell carcinomas.

vs. 1.23-fold in BCCs, $\mathrm{P}=0.0003$; Fig. 4B). Differences in Fas ligand protein expression levels (Fig. 4C) followed the same pattern as the corresponding mRNA expression levels (Fig. 4B).

Caspase- 8 , is a downstream target of Fas ligand signaling and an initiator for the extrinsic apoptotic pathway (29). JAG1 treatment slightly decreased the protein expression levels of cleaved caspase- 8 in HRSCs, but induced a significant increase in cleaved caspase- 8 in BCCs (Fig. 4D), suggesting the caspase-dependent pathway was involved in BCC cell apoptosis induced by JAG1.

\section{Discussion}

The present study considered the potential relationships between HFs and BCCs, with reference to the similarities/differences in signaling pathway activation. Gene functions and the specific involvement of the Notch and Shh signaling pathways were surveyed to define how these regulatory pathways may control $\mathrm{HF}$ and BCC growth (30). Defining gene expression patterns and pathways in BCCs that are distinct from HF growth and cycling may lead to a better understanding of the abnormal proliferation that these cells undergo in the development of skin cancer.

Genes similarly expressed in HFs and BCCs were found under the same functional GO categories, including 'positive regulation of cellular process' and 'regulation of multicellular organismal process'. This suggested that common regulatory genes may be important for the morphogenesis of both skin appendages. By contrast, a number of genes were uniquely expressed in HFs or BCCs only. These genes may serve as stage-specific signatures of appendage formation, either for maintaining and regenerating normal HFs, or for the formation of tumor masses. Commonly and differentially expressed genes related to morphogenesis are consistent with our hypothesis that BCC tumors may follow an abnormal appendage development process that exhibits elements of consistent order, morphogenesis and patterning as observed in HFs.

Shh signaling is required for the proliferation and normal cycling of HF epithelium. Modifications of Shh signaling can lead to tumor development in tissues of different origins (13). Hyperactivation of the Shh signaling pathway is found in several HF derived tumors and in BCCs $(31,32)$. Overexpression of GLII and GLI2 products are also common features of BCCs, and suggests increased Shh signaling $(31,33)$. Consistent with previous findings $(31,33)$, the expression of $G L I 1$ and $G L I 2$ was enhanced in BCCs and HF root sheaths, compared with normal skin. However, the HF root sheaths exhibited significantly higher expression levels of GLII and GLI2 compared with BCCs. Shh signaling pathway genes may influence the same progenitor cells in BCCs and HFs, but the different gene activation levels in the two tissue types may contribute to the divergent patterns of growth.

Differential expression of the Notch signaling pathway was also revealed in BCCs and HFs compared with each other and with normal skin. The Notch pathway, with its family of four mammalian Notch receptors and their numerous ligands 

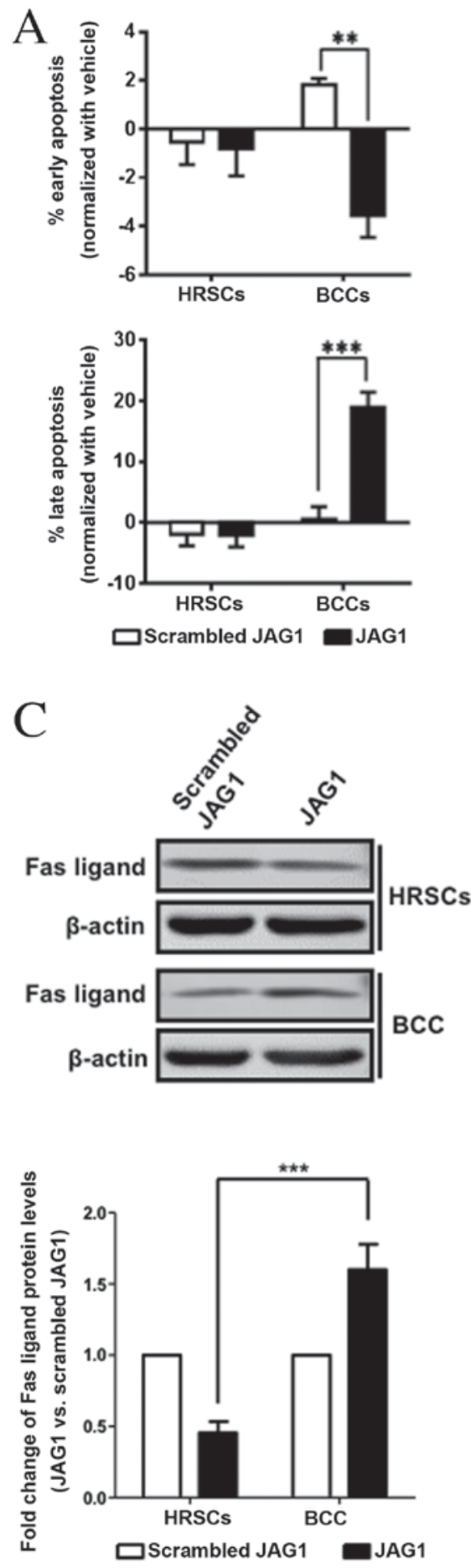

B
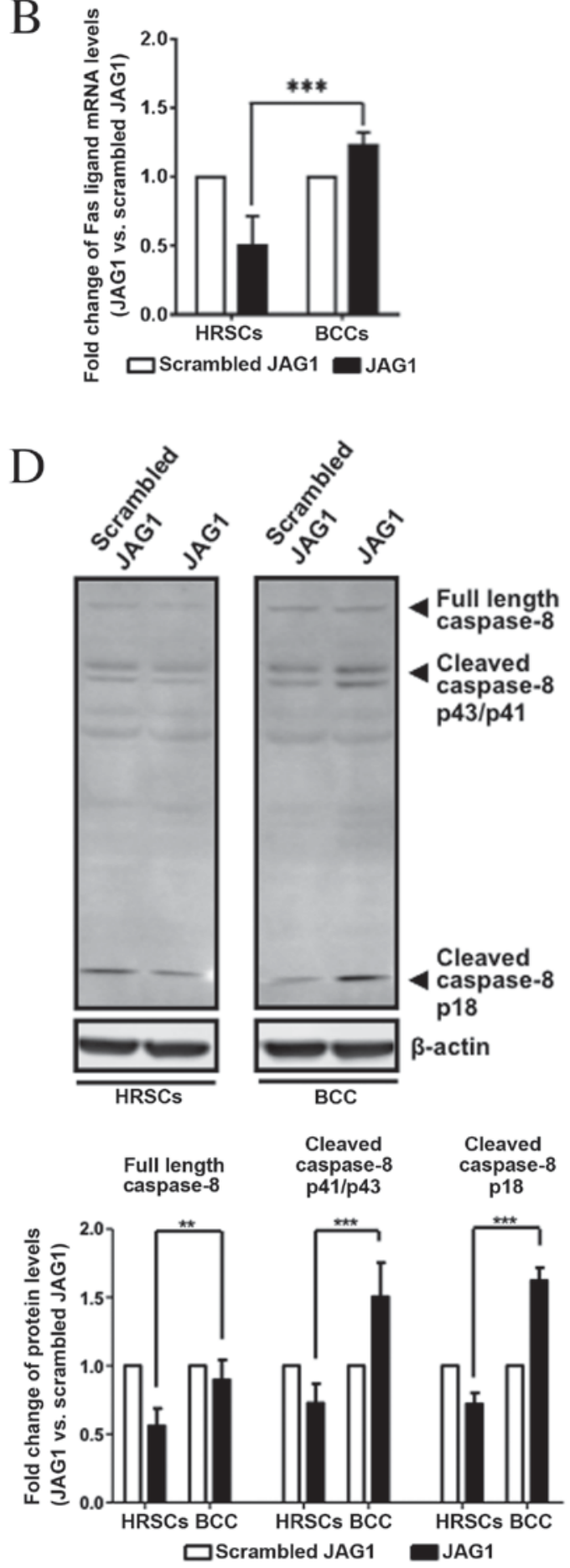

Figure 4. JAG1 treatment induced BCC cell apoptosis via Fas ligand. HRSCs or BCCs were treated with 4 mM JAG1 or scrambled peptide for 3 days. (A) Percentage of apoptotic cells was quantified by Annexin V-PI labeling and flow cytometric analysis. (B) Fas ligand mRNA expression levels were measured by qPCR. Representative data from three independent experiments are shown. Protein expression levels of (C) Fas ligand and (D) caspase-8 in treated HRSCs or BCCs were measured by western blot analysis. $\beta$-actin was used as the internal control. Levels of Fas ligand or caspase- 8 proteins levels were normalized to the levels of $\beta$-actin protein, and are expressed as fold change relative to control (scrambled JAG1). Data are presented as the mean \pm standard deviation of three independent experiments. ${ }^{* *} \mathrm{P}<0.01$ and ${ }^{* * *} \mathrm{P}<0.001$, comparisons indicated by brackets. HRSCs, human hair follicle root sheath cells; BCCs, basal cell carcinomas; JAG1, Jagged1.

of the Delta, Jagged, and Serrate groups, is important for cell fate determination and organogenesis during embryonic development $(34,35)$. Studies on embryonic mice and rats have demonstrated that the Notch/recombining binding protein suppressor of hairless (RBP-J) signaling pathway promotes epidermal differentiation (12) and cutaneous appendage patterning (36). Aberrant Notch signaling has been linked to a wide variety of tumors, but Notch can either suppress or promote tumors depending on the cell type and context $(37,38)$. Jayaraman et al (14) demonstrated that $\mathrm{NOTCHI}$ and $\mathrm{NOTCH} 2$ were significantly mutated in BCCs. The present study indicated that selected Notch pathway genes 
were differentially activated and inhibited in BCCs, which may be due to positive feedback, and reciprocal negative feedback, from differences in Delta and Notch cell surface expression, or the irregular activation of downstream Notch signaling pathway genes.

Examination of downstream components of the Notch pathway revealed more interesting results: The transcription factor RBP-J and downstream target genes of the Hes and Deltex families, exhibited a high expression in hair shafts compared with BCCs and normal skin. By contrast, two genes that affect the co-repression of RBP-J, CTBP1 and CREBBP, were observed to have a significantly lower expression in HFs compared with BCCs (data not shown). Deletion of RBP-J from follicular stem cells results in an aberrant cell fate switch that leads to the establishment of epidermal progenitors and basal cells (39). This result, therefore, demonstrated that the Notch/RBP-J signaling pathway is strongly activated in HFs. Since the Notch signaling pathway promotes a stem cell phenotype in skin (36), the degree of Notch signaling pathway activation may be important for HF stem cell proliferation and differentiation. The high level of Notch/RBP-J signaling pathway activation may be required for the formation and maintenance of follicles.

The present study suggests a lack of downstream gene expression in the Notch/RBP-J signaling pathway in BCCs. This may allow basal cells to escape from the normal regulation of proliferation that is normally found in the absence of Notch signaling, as observed in mammary epithelium cell lineages (40). Loss of RBP-J action in BCCs may promote cells towards a more stem, or progenitor, cell-like status, enabling basal cell tumor growth. Notch signaling via Notch receptor intracellular domain translocation into the nucleus, and subsequent binding to the transcription factor RBP-J, may be an important stage in the regulation of BCC development. As such, RBP-J signaling may be a focus for the development of new BCC therapies, as has been suggested for other types of cancer (41-44).

Fas ligand is a type II transmembrane protein that can induce apoptosis upon binding to Fas. Compared with normal skin, Fas ligand mRNA expression levels have previously been demonstrated to be lower in BCC specimens and immunostainings were weak or undetected (45). The present findings have shown that activation of the Notch signaling pathway by adding exogenous JAG1 into BCC cell culture resulted in increased Fas ligand mRNA and protein expression. This further activated downstream caspase- 8 to initiate BCC cell apoptosis. However, some tumors can decrease Fas expression to resist Fas ligand-mediated T-cell cytotoxicity, and simultaneously upregulate the expression of Fas ligand to induce apoptosis in Fas-expressing T cells (46). BCCs strongly express Fas ligand, which may help prevent attack from surrounding immune effector cells, while also lacking Fas, potentially to make the tumor cells resistant to apoptosis (47). Further investigation is required to characterize the exact role of elevated Fas ligand expression induced by Notch signaling activation by in vivo experiments.

Notch signaling pathway genes are important in HF formation and BCC neoplasia. Hair follicles can develop from skin stem cells or their progeny, in a patterning program that is controlled by multiple signaling pathways, function processes and other components. Skin stem cells that are regulated by multiple signaling pathways, normal function processes and normal components, may allow BCCs to develop through abnormal activation order, irregular cell cycle timing and aberrant activation of multiple signaling pathways.

In summary, the present study suggests that controlling the Notch/RBP-J signaling pathway may stop the dysregulation of cell proliferation and differentiation to BCC skin cancer. The degree of Notch signaling pathway activation may also be important in HF formation. Elements of the Notch pathway are potentially worthwhile targets for future treatment of BCCs and, as a corollary, in HF engineering.

\section{Acknowledgements}

The present study was financially supported by the Canadian Dermatology Foundation and the Canadian Institutes of Health Research (CIHR; grant nos. MUS-94025 and MSH-95328). We would like to thank the staff of the Microarray Facility of The Prostate Centre at Vancouver General Hospital for their technical assistance and advice. We would also like to extend thanks to Drs. H. Lui and S. Le Bihan for their assistance and advice.

\section{References}

1. Tiede S and Paus R: Lhx2-decisive role in epithelial stem cell maintenance, or just the 'tip of the iceberg'? Bioessays 28: 1157-1160, 2006.

2. Alonso L and Fuchs E: Stem cells of the skin epithelium. Proc Natl Acad Sci USA 100: (Suppl 1) 11830-11835, 2003.

3. Honeycutt KA, Koster MI and Roop DR: Genes involved in stem cell fate decisions and commitment to differentiation play a role in skin disease. J Investig Dermatol Symp Proc 9: 261-268, 2004.

4. Najafzadeh N, Esmaeilzade B and Dastan Imcheh M: Hair follicle stem cells: In vitro and in vivo neural differentiation. World J Stem Cells 7: 866-872, 2015.

5. Burkert J, Wright NA and Alison MR: Stem cells and cancer: An intimate relationship. J Pathol 209: 287-297, 2006.

6. Jahoda C and Reynolds A: Skin stem cells-a hairy issue. Nat Med 6: 1095-1097, 2000.

7. Crowson AN: Basal cell carcinoma: Biology, morphology and clinical implications. Mod Pathol 19: (Suppl 2) S127-S147, 2006.

8. Grachtchouk M, Pero J, Yang SH, Ermilov AN, Michael LE, Wang A, Wilbert D, Patel RM, Ferris J, Diener J, et al: Basal cell carcinomas in mice arise from hair follicle stem cells and multiple epithelial progenitor populations. J Clin Invest 121: 1768-1781, 2011.

9. Lopez-Takegami JC, Wolter M, Löser C, Maiweg C, Jones M, Metze D and Böer-Auer A: Classification of cysts with follicular germinative differentiation. J Cutan Pathol 43: 191-199, 2016.

10. Peterson SC,Eberl M, Vagnozzi AN, Belkadi A, Veniaminova NA, Verhaegen ME, Bichakjian CK, Ward NL, Dlugosz AA and Wong SY: Basal cell carcinoma preferentially arises from stem cells within hair follicle and mechanosensory niches. Cell Stem Cell 16: 400-412, 2015.

11. Hutchin ME, Kariapper MS, Grachtchouk M, Wang A, Wei L, Cummings D, Liu J, Michael LE, Glick A and Dlugosz AA: Sustained Hedgehog signaling is required for basal cell carcinoma proliferation and survival: Conditional skin tumorigenesis recapitulates the hair growth cycle. Genes Dev 19: 214-223, 2005.

12. Thélu J, Viallet JP and Dhouailly D: Differential expression pattern of the three Fringe genes is associated with epidermal differentiation. J Invest Dermatol 111: 903-906, 1998.

13. McMahon AP, Ingham PW and Tabin CJ: Developmental roles and clinical significance of hedgehog signaling. Curr Top Dev Biol 53: 1-114, 2003.

14. Jayaraman SS, Rayhan DJ, Hazany S and Kolodney MS: Mutational landscape of basal cell carcinomas by whole-exome sequencing. J Invest Dermatol 134: 213-220, 2014. 
15. Wuest M, Dummer R and Urosevic M: Induction of the members of Notch pathway in superficial basal cell carcinomas treated with imiquimod. Arch Dermatol Res 299: 493-498, 2007.

16. Rishikaysh P, Dev K, Diaz D, Qureshi WM, Filip S and Mokry J: Signaling involved in hair follicle morphogenesis and development. Int J Mol Sci 15: 1647-1670, 2014.

17. Lyons P: Advances in spotted microarray resources for expression profiling. Brief Funct Genomic Proteomic 2: 21-30, 2003

18. Nelson CC, Hoffart D, Gleave ME and Rennie PS: Application of gene microarrays in the study of prostate cancer. Methods Mol Med 81: 299-320, 2003.

19. Mungamuri SK, Yang X, Thor AD and Somasundaram K: Survival signaling by Notch1: Mammalian target of rapamycin (mTOR)-dependent inhibition of p53. Cancer Res 66: 4715-4724, 2006.

20. Tusher VG, Tibshirani R and Chu G: Significance analysis of microarrays applied to the ionizing radiation response. Proc Natl Acad Sci USA 98: 5116-5121, 2001.

21. Rizzo P, Miao H, D'Souza G, Osipo C, Song LL, Yun J, Zhao H, Mascarenhas J, Wyatt D, Antico G, et al: Cross-talk between notch and the estrogen receptor in breast cancer suggests novel therapeutic approaches. Cancer Res 68: 5226-5235, 2008.

22. Huang da W, Sherman BT and Lempicki RA: Bioinformatics enrichment tools: Paths toward the comprehensive functional analysis of large gene lists. Nucleic Acids Res 37: 1-13, 2009.

23. Huang DW, Sherman BT and Lempicki RA: Systematic and integrative analysis of large gene lists using DAVID bioinformatics resources. Nat. Protocols 4: 44-57, 2009.

24. Harris MA, Clark J, Ireland A, Lomax J, Ashburner M, Foulger R, Eilbeck K, Lewis S, Marshall B, Mungall C, et al: The Gene Ontology (GO) database and informatics resource. Nucleic Acids Res 32: D258-D261, 2004.

25. Huang da W, Sherman BT, Tan Q, Collins JR, Alvord WG, Roayaei J, Stephens R, Baseler MW, Lane HC and Lempicki RA: The DAVID gene functional classification tool: A novel biological module-centric algorithm to functionally analyze large gene lists. Genome Biol 8: R183, 2007.

26. Livak KJ and Schmittgen TD: Analysis of relative gene expression data using real-time quantitative PCR and the 2(-Delta Delta C (T)) Method. Methods 25: 402-408, 2001

27. Lo BK, Yu M, Zloty D, Cowan B, Shapiro J and McElwee KJ: CXCR3/ligands are significantly involved in the tumorigenesis of basal cell carcinomas. Am J Pathol 176: 2435-2446, 2010.

28. Rooman I, De Medts N, Baeyens L, Lardon J, De Breuck S, Heimberg $\mathrm{H}$ and Bouwens L: Expression of the Notch signaling pathway and effect on exocrine cell proliferation in adult rat pancreas. Am J Pathol 169: 1206-1214, 2006.

29. Holtzman MJ, Green JM, Jayaraman S and Arch RH: Regulation of T cell apoptosis. Apoptosis 5: 459-471, 2000.

30. Katoh M and Katoh M: Notch ligand, JAG1, is evolutionarily conserved target of canonical WNT signaling pathway in progenitor cells. Int J Mol Med 17: 681-685, 2006.

31. Dahmane N, Lee J, Robins P, Heller P and Ruiz i Altaba A: Activation of the transcription factor Gli1 and the Sonic hedgehog signalling pathway in skin tumours. Nature 389: 876-881, 1997.
32. Oro AE, Higgins KM, Hu Z, Bonifas JM, Epstein EH Jr and Scott MP: Basal cell carcinomas in mice overexpressing sonic hedgehog. Science 276: 817-821, 1997.

33. Grachtchouk M, Mo R, Yu S, Zhang X, Sasaki H, Hui CC and Dlugosz AA: Basal cell carcinomas in mice overexpressing Gli2 in skin. Nat Genet 24: 216-217, 2000.

34. Artavanis-Tsakonas S, Rand MD and Lake RJ: Notch signaling: Cell fate control and signal integration in development. Science 284: 770-776, 1999 .

35. Ayaz F and Osborne BA: Non-canonical notch signaling in cancer and immunity. Front Oncol 4: 345, 2014.

36. Lowell S, Jones P, Le Roux I, Dunne J and Watt FM: Stimulation of human epidermal differentiation by delta-notch signalling at the boundaries of stem-cell clusters. Curr Biol 10: 491-500, 2000.

37. Chappell WH, Green TD, Spengeman JD, McCubrey JA, Akula SM and Bertrand FE: Increased protein expression of the PTEN tumor suppressor in the presence of constitutively active Notch-1. Cell Cycle 4: 1389-1395, 2005.

38. Nicolas M, Wolfer A, Raj K, Kummer JA, Mill P, van Noort M, Hui CC, Clevers H, Dotto GP and Radtke F: Notch1 functions as a tumor suppressor in mouse skin. Nat Genet 33: 416-421, 2003.

39. Yamamoto N, Tanigaki K, Han H, Hiai H and Honjo T: Notch/ RBP-J signaling regulates epidermis/hair fate determination of hair follicular stem cells. Curr Biol 13: 333-338, 2003.

40. Buono KD, Robinson GW, Martin C, Shi S, Stanley P, Tanigaki K, Honjo T and Hennighausen L: The canonical Notch/ RBP-J signaling pathway controls the balance of cell lineages in mammary epithelium during pregnancy. Dev Biol 293: 565-580, 2006.

41. Garber K: Notch emerges as new cancer drug target. J Natl Cancer Inst 99: 1284-1285, 2007.

42. Purow B: Notch inhibition as a promising new approach to cancer therapy. Adv Exp Med Biol 727: 305-319, 2012.

43. Yabuuchi S, Pai SG, Campbell NR, de Wilde RF, De Oliveira E, Korangath P, Streppel MM, Rasheed ZA, Hidalgo M, Maitra A and Rajeshkumar NV: Notch signaling pathway targeted therapy suppresses tumor progression and metastatic spread in pancreatic cancer. Cancer Lett 335: 41-51, 2013.

44. Yan B, Liu L, Zhao Y, Xiu LJ, Sun DZ, Liu X, Lu Y, Shi J, Zhang YC, Li YJ, et al: Xiaotan Sanjie decoction attenuates tumor angiogenesis by manipulating Notch-1-regulated proliferation of gastric cancer stem-like cells. World J Gastroenterol 20: 13105-13118, 2014

45. Wang XY, Zhang R and Lian S: Aberrant expression of Fas and FasL pro-apoptotic proteins in basal cell and squamous cell carcinomas. Clin Exp Dermatol 36: 69-76, 2011.

46. Satchell AC, Barnetson RS and Halliday GM: Increased Fas ligand expression by $T$ cells and tumour cells in the progression of actinic keratosis to squamous cell carcinoma. Br J Dermatol 151: 42-49, 2004.

47. Erb P, Ji J, Wernli M, Kump E, Glaser A and Buchner SA: Role of apoptosis in basal cell and squamous cell carcinoma formation. Immunol Lett 100: 68-72, 2005. 